\title{
The genomic architecture of disease resistance in lettuce
}

Leah K. McHale • Maria José Truco • Alexander Kozik · Tadeusz Wroblewski •

Oswaldo E. Ochoa $\cdot$ Kirsten A. Lahre $\cdot$ Steven J. Knapp $\cdot$ Richard W. Michelmore

Published online: 20 March 2009

(C) Springer-Verlag 2009

Erratum to: Theor Appl Genet (2009) 118:565-580

DOI 10.1007/s00122-008-0921-1

Unfortunately, Fig. 3 of this article had incorrect marker names on the genetic map due to a frameshift in the data that occurred while correcting the proofs. The correct version is given on the following page.

The online version of the original article can be found under doi:10.1007/s00122-008-0921-1.

L. K. McHale · M. J. Truco · A. Kozik · T. Wroblewski

O. E. Ochoa $\cdot$ K. A. Lahre $\cdot$ R. W. Michelmore $(\square)$

The Genome Center and Department of Plant Sciences,

University of California, Davis, CA 95616, USA

e-mail: rwmichelmore@ucdavis.edu

L. K. McHale

e-mail: lkmchale@ucdavis.edu

\section{S. J. Knapp}

Institute of Plant Breeding, Genetics and Genomics,

Center for Applied Genetic Technologies,

University of Georgia, Athens, GA 30602, USA 
1

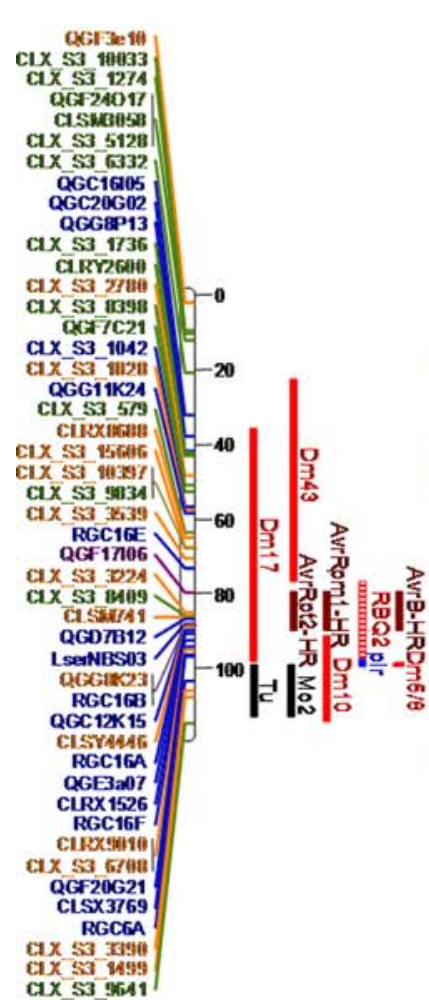

cax so 1941
2

3a

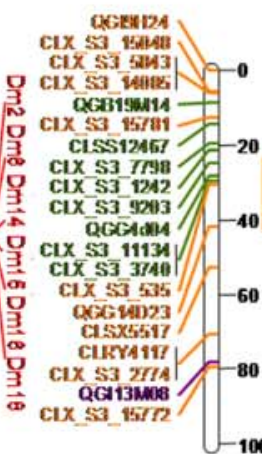$$
\text { cix } 5 \bar{x} \text { y }
$$

c1X 53 ir/1
c1x 53 gart

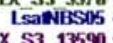

CLX_S3_13590

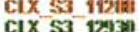

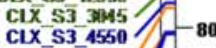

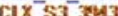

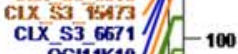

QGI11K10

cix 53 7 7 A

$\left.\begin{array}{c}\cos 53 \text { 4212 } \\ \cos 53 \text { 15231 }\end{array}\right] / V_{-120}$

$\underset{\operatorname{cog} 22819}{\operatorname{ar} 53116}$

c1x s3 v216 1 - 140

$c 1 x \leqslant 3$ 8xsy

CIX 53 AMa1
C1X 53 7749

C1X 53 ans

CXX 53 iv1

CIX 535919

QGF20EИ

cix_53 7M7

cix s3 5313
4

5

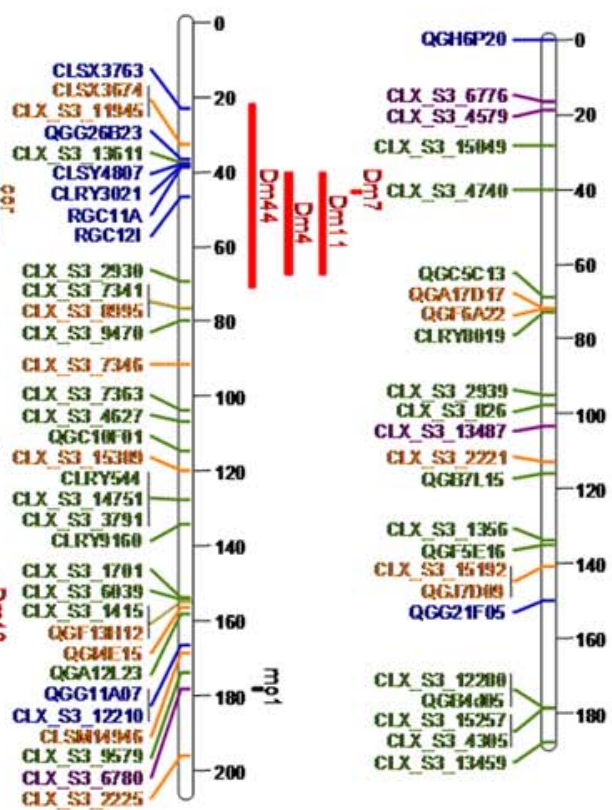

6

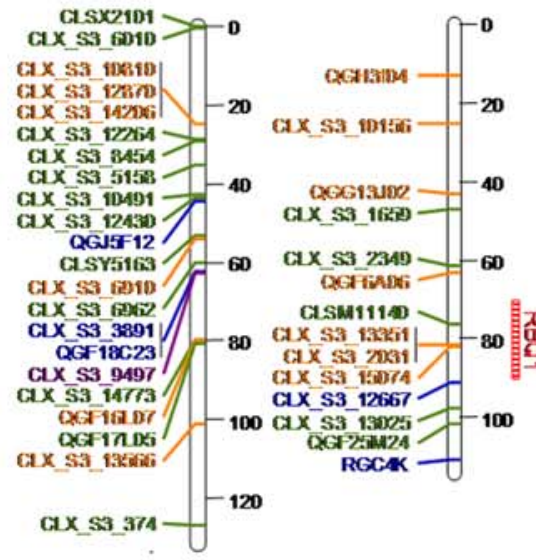

7

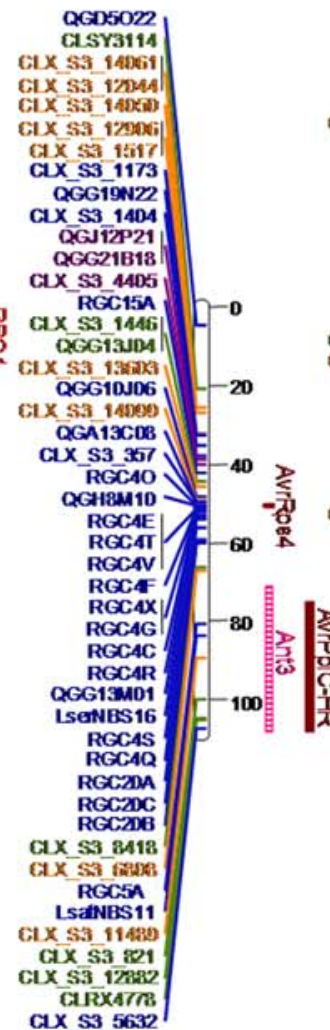

8
9

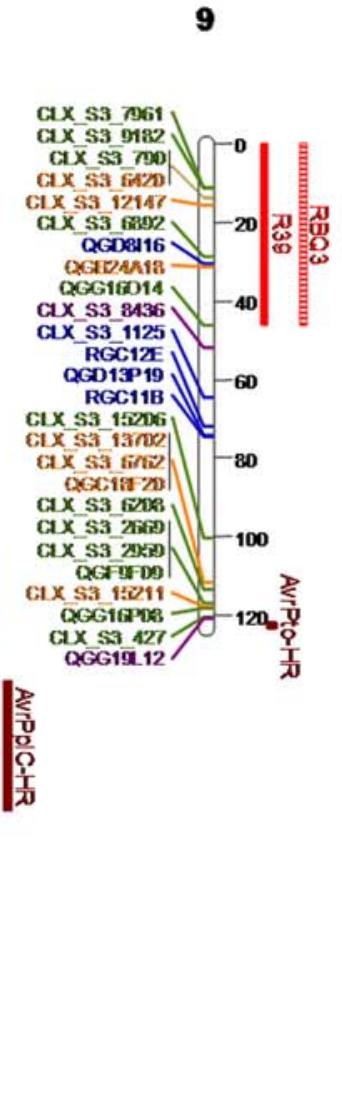

LEEEND:

Resistance candidate genes:

- Pathogen recognition

- Resistance signaling pattway

Defense response

Susceptibity factor

Resistance phenotypes:

I Downy mildew

I Virus

Anthracnose

Root aphid

| Plasmopora kactucae-radicis

Corky root

| Effector HR

貝Quantitative trait Loci

Fig. 3 Lettuce genetic map displaying 294 mapped candidate resistance genes and 35 resistance phenotypes. Sequence names have been abbreviated for display, see S1 for full names. Figure created with MapChart (Voorrips 2002) 